\title{
CHROMOSOME NUMBER POLYMORPHISM IN THE SAWFLY JANUS INTEGER (HYMENOPTERA, CEPHIDAE)*
}

\author{
By R. H. Crozier and E. F. Taschenberg
}

Department of Zoology, University of Georgia, Athens, Georgia; and Vineyard Laboratory, New York State Experiment Station, Fredonia, New York.

\section{INTRODUCTION}

The Symphytan family Cephidae has a special significance in the study of the evolution of the Hymenoptera, as it is belived to be the group closest to the stem from which the Apocrita evolved. The chromosomes of only one cephid, Cephus cinctus, have been described previously (Mackay, I955); the Cephidae are therefore an important but cytogenetically little-known group.

\section{MeTHods}

Male pupae of Janus integer were obtained by allowing virgin females to oviposit on caged currant bushes from which all the previous year's growth had been removed.

Chromosome preparations were made from pupal or prepupal testes using an air-drying technique (Crozier, 1968, 1970). Each prepupa or pupa was punctured using a minuten pin and placed with the puncture touching a drop of a $0.05 \%$ solution of colcemid in an insect Ringer solution and left overnight. The next day the testes were dissected out under a $\mathrm{r} \% \mathrm{w} / \mathrm{v}$ sodium citrate solution and left in the solution for 20 minutes; they were then fixed in $3: 1$ methanol-acetic acid fixative for at least 45 minutes. The cells were dissociated using a drop of $60 \%$ acetic acid on a warm slide and the suspension spread using further methanol-acetic fixative before being dried by an air-flow and stained using aceto-lactic orcein. The preparations were dehydrated and mounted in 'Euparal'.

The chromosomes of intact cells were counted using a hand counter. If a majority of cells had shown the same number after 20 cells, and none had been found with a higher number, that number was taken to be the chromosome number of that individual. Otherwise, further cells were counted.

\section{Results and Discussion}

The karyotypes of eight male Janus integer were determined. Two

\footnotetext{
* Manuscript received by the editor March 3, 1972.
} 


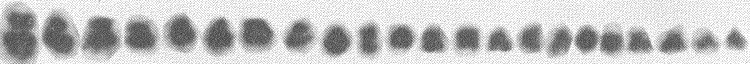

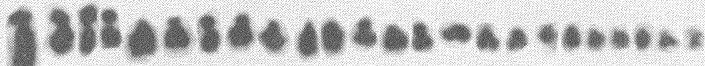

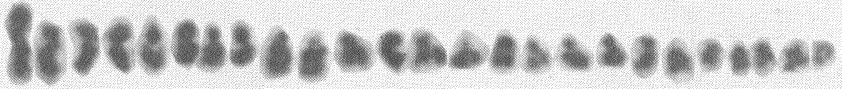

Figure 1. Karyotypes of 22, 24 and 26 chromosomes of Janus integer.

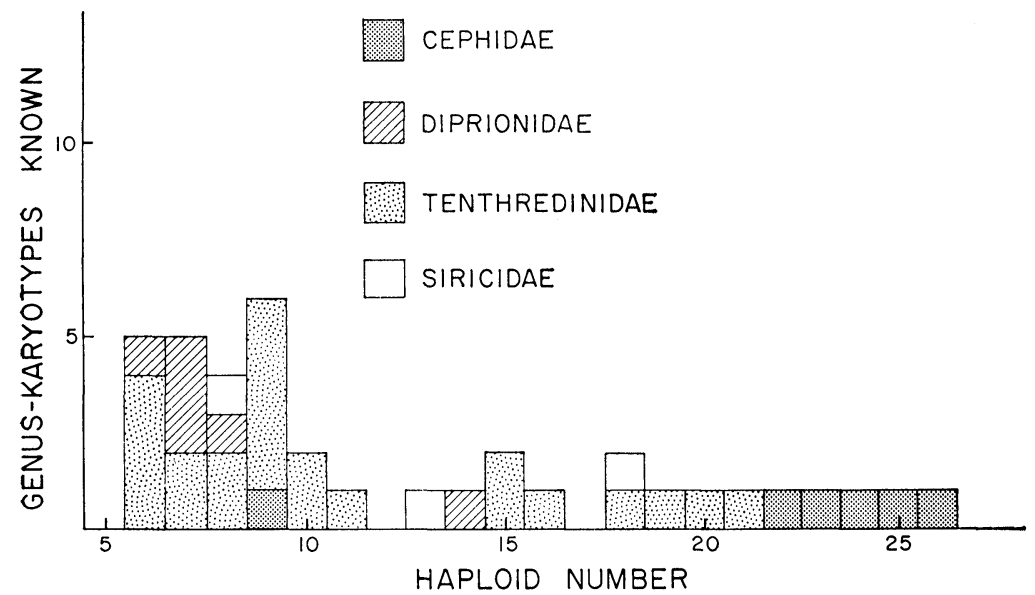

Figure 2. Genus-karyotypes of Symphyta, based on published data (Sanderson, 1971; Nogusa, 1965; Waterhouse and Sanderson, 1958; Comrie, 1938; Maxwell, 1958; Mackay, 1955). Benson's (1950) review does not give sources for the counts given, and Sanderson's (1932) counts were later shown by her (Sanderson, 1971) to be in error; counts from before these two and pre-1932 sources have therefore been omitted. 
had a chromosome number of 22 , three had one of 24 , two had one of 25, and one had one of 26. Karyotypes of 22, 24 and 26 chromosomes are shown in Figure $\mathrm{I}$. Because of the small size of the chromosomes, we could not determine the nature of the polymorphism, but Robertsonian changes do not appear to be involved. The range of chromosome numbers between 22 and 26 is probably continuous, with the lack of a count of 23 being due to sample error.

This is the second report of intraspecific variation in chromosome numbers in Symphyta. Sanderson (I97I) reports that, while English collections of Tenthredo acerrima consistently had a haploid number of $\mathrm{I} 8$, Scottish collections had haploid numbers ranging from $\mathrm{I} 8$ to $2 \mathrm{I}$. There is thus a geographic basis to the $T$. acerrima polymorphism that remains to be searched for in J. integer.

Chromosome numbers in the Apocrita range from four to 28, which range is found in the single family Formicidae (Crozier, I970). The low haploid number $(n=9)$ (Mackay, I955) of Cephus cinctus, combined with the fact that generally lower numbers have been reported for Parasitica than for Aculeata, suggested that low numbers might be primitive in the Apocrita. However, the discovery that another cephid, Janus integer, has high chromosome numbers indicates that high numbers are as likely to be a primitive character in the Apocrita as low numbers.

Karyotype frequencies are best considered using the genus-karyotype concept (Crozier, 1970), in order to minimize the effects of different intensities of sampling between genera. Under this convention, each chromosome number is counted once each time it occurs in a genus, irrespective of how many species it occurs in. The genus-karyotypes known for the Symphyta are shown in figure 2, where it can be seen that Janus integer has the highest chromosome number of any sawfly. The distribution of genus-karyotypes is strongly skewed, suggesting that low numbers might be primitive for the Symphyta. The ranges in chromosome numbers of the families Tenthredinidae and Cephidae are particularly striking. The gaps in these ranges might indicate polyploidy, but the karyotypes of too few species are known to give much support to this suggestion.

\section{SumMary}

Eight males of Janus integer had haploid numbers of 22, 24, 25 and 26; presumably a larger sample would have yielded counts of 23 as well. The polymorphism does not appear to be Robertsonian in nature. The significance of these results to considerations of hymenopteran karyotypic evolution is discussed. 


\section{REFERENCES}

Benson, R. B.

1950. An introduction to the natural history of British sawflies. Trans.

COMrie, L. C. Soc. Brit. Entomol., 10: 45-142.

1938. Biological and cytological observations on tenthredinid parthenogenesis. Nature, 142: 877-878.

Crozier, R. H.

1968. An acetic acid dissociation, air-drying technique for insect chromosomes, with acetolactic orcein staining. Stain Technol., 43: 171-173.

1970. Karyotypes of twenty-one ant species (Hymenoptera: Formicidae), with reviews of the known ant karyotypes. Canad. J. Genet. Cytol., 12: 109-128.

Mackay, M. R.

1955. Cytology and parthenogenesis of the Wheat Stem Sawfly, Cephus cinctus Nort. (Hymenoptera: Cephidae). Canad. J. Zool., 33 : 161-174.

MaXwell, D. E.

1958. Sawfly cytology with emphasis upon the Diprionidae (Hymenoptera: Symphyta). Proc. 10th Intern. Congr. Entomol. (1956) 2: 961-978.

Nogusa, S.

1965. Chromosome observations of leaf bees (Hymenoptera: TenthreSANDERSon, A. R. dinidae). Dobutsugaku Zasshi, 74:372-373 (in Japanese).

1932. The cytology of parthenogenesis in Tenthredinidae. Genetica, 14: 321-451.

1971. Further studies on the cytology of sawflies. Proc. Roy. Soc. Edinb., B7 1: 29-40.

SLINGERLAND, M. V.

1897. The currant stem girdler and the raspberry cane maggot. N. Y. (Cornell) Agr. Exper. Sta. Bull., 126: 41-53.

Waterhouse, F. L. and A. R. SANDerson

1958. Geographic colour polymorphism and chromosome constitution in sympatric species of sawflies. Nature, 182: 477. 

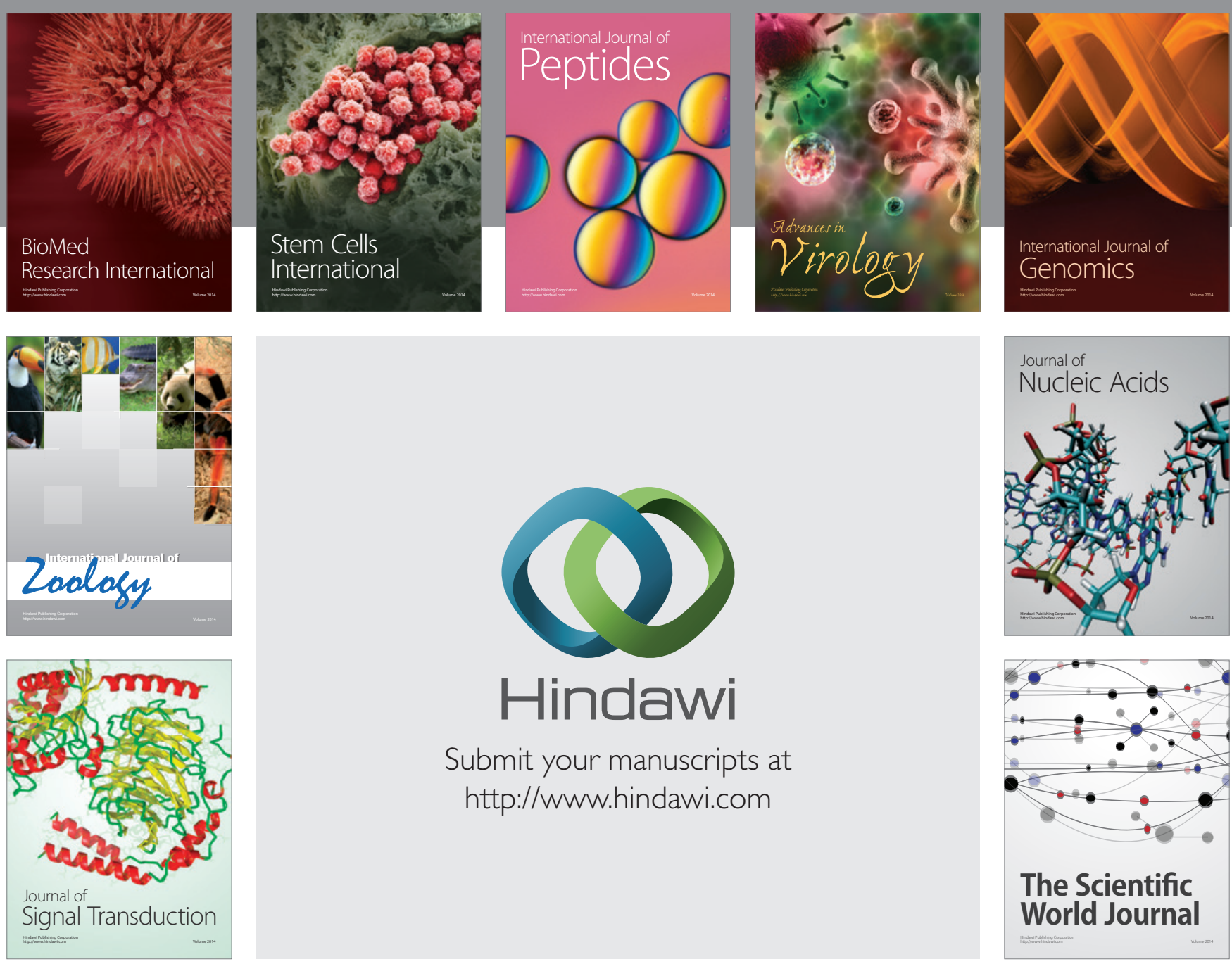

Submit your manuscripts at

http://www.hindawi.com
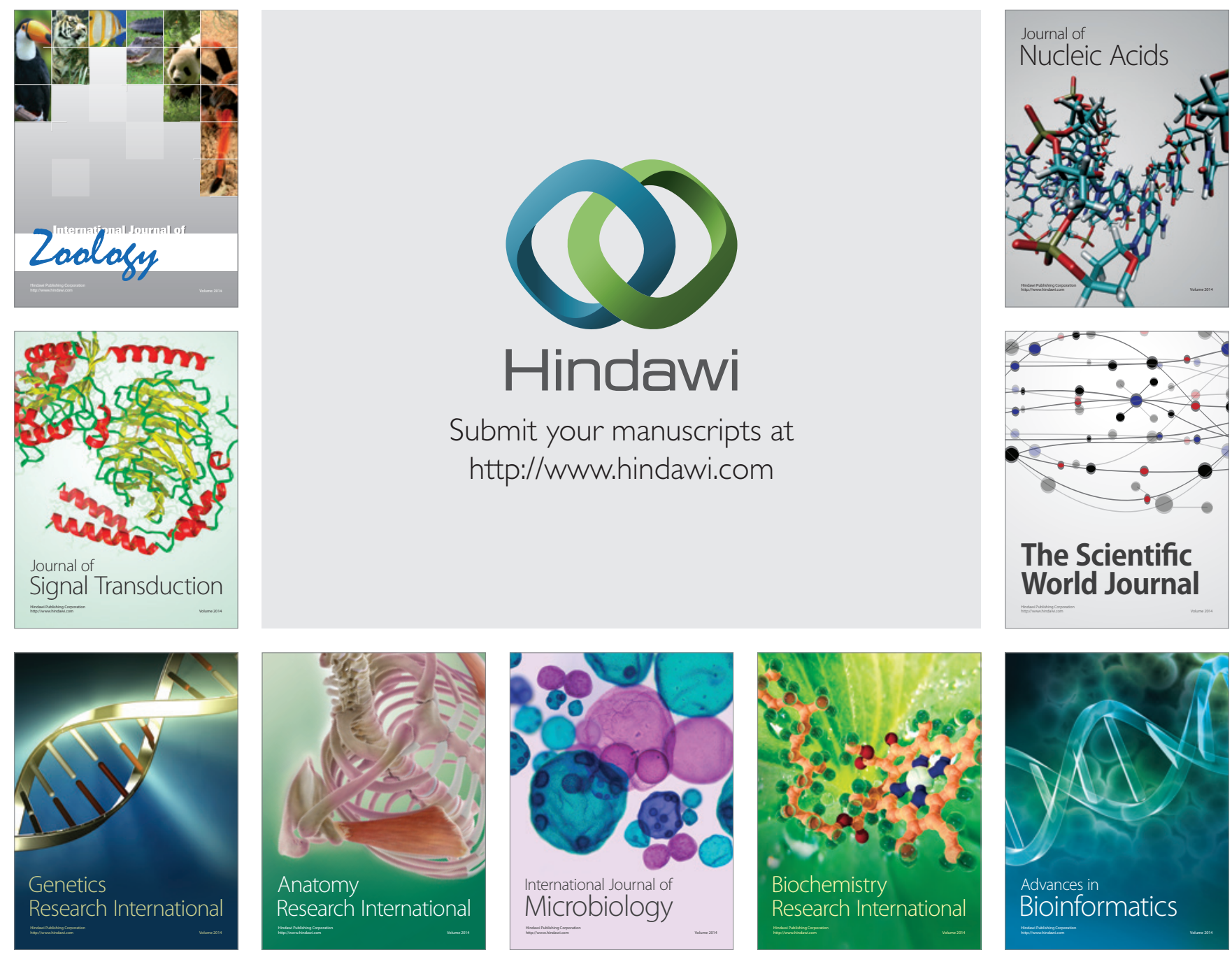

The Scientific World Journal
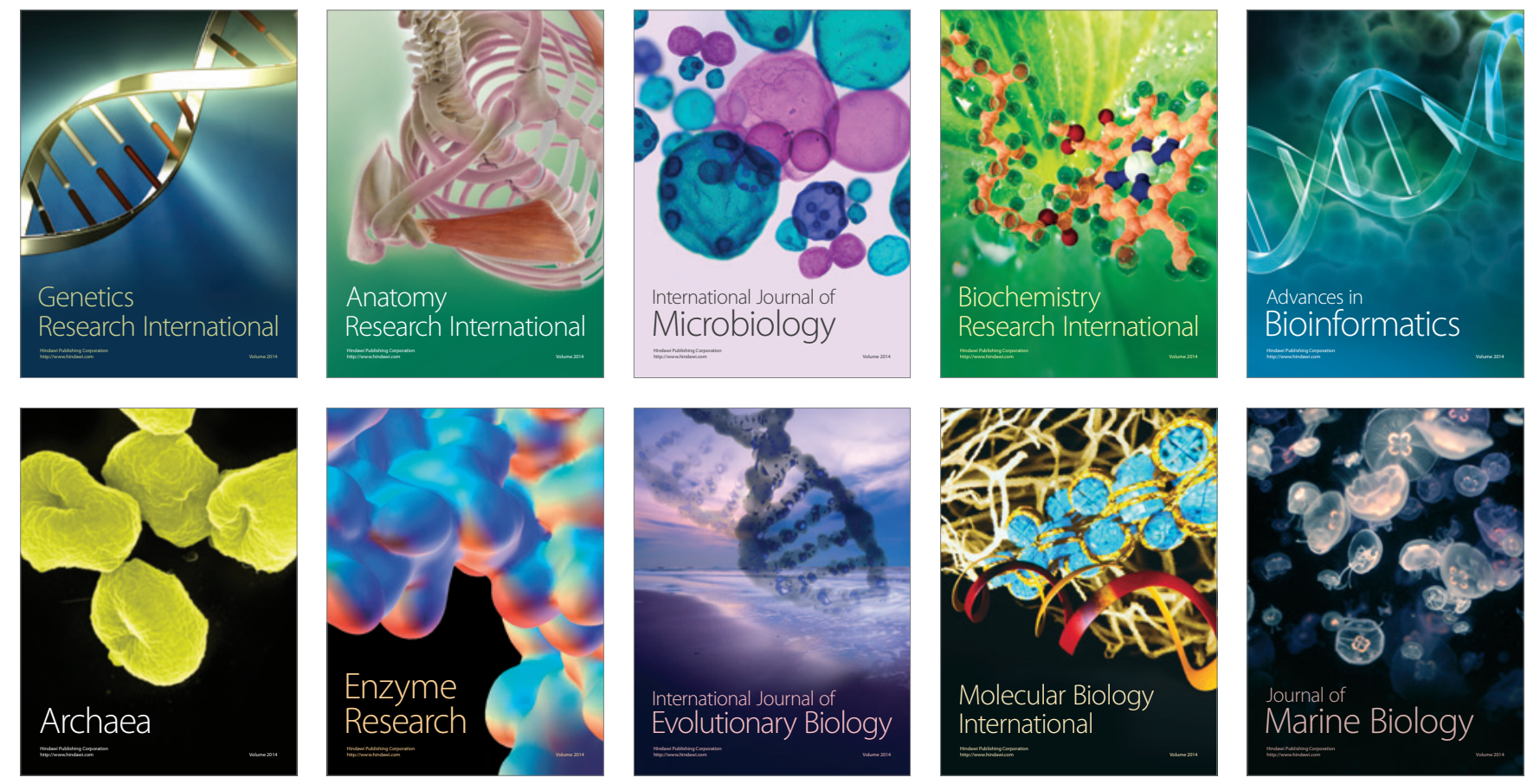